POLLACK PERIODICA

An International Journal for Engineering and Information Sciences

DOI: $10.1556 / 606.2017 .12 .2 .8$

Vol. 12, No. 2, pp. 91-102 (2017)

www.akademiai.com

\title{
PVA-PAA HYDROGEL MICRO-CARRIER FOR THE IMPROVEMENT OF PHASE SEPARATION EFFICIENCY OF BIOMASS IN WASTEWATER TREATMENT
}

\author{
${ }^{1}$ Dániel Benjámin SÁNDOR, ${ }^{2}$ Anita SZABÓ, ${ }^{3}$ Ernő FLEIT, \\ ${ }^{4}$ Zoltán BAKACSI, ${ }^{5}$ Gergő ZAJZON \\ 1,2,4,5Inno-Water Inc. H-1237 Budapest, Sósmocsár út 9. II. em. 3, Hungary \\ e-mail: ${ }^{1}$ sandor.daniel@innowater.hu, ${ }^{2}$ szabo.anita@innowater.hu, \\ ${ }^{4}$ bakacsi.zoltan@innowater.hu, ${ }^{5}$ zajzon.gergo@innowater.hu \\ ${ }^{3}$ Eötvös József College, Institute of Water Supply and Environmental Engineering \\ H-6500 Baja, Bajcsy-Zsilinszky Endre utca 14, Hungary \\ e-mail: ${ }^{3}$ fleit.erno@ejf.hu
}

Received 27 November 2016; accepted 2 February 2017

\begin{abstract}
Phase separation process is influenced by operational factors that can hardly be controlled. This paper demonstrates the results of a series of experiments aiming to solve these problems using polyvinyl-alcohol - poly-acrylic acid copolymer hydrogel micro-carrier for the adherence of microorganisms to achieve better settling properties of the biomass. The nitrification process was examined using hydrogel micro-carriers and conventional activated sludge flocks. The sedimentation properties of the two systems were compared indifferent conditions. Results show that the sedimentation properties of the immobilized system were more favorable than activated sludge flocks.
\end{abstract}

Keywords: Hydrogel, Biofilm, Sedimentation tests, Micro-carrier, Filamentous organisms, Wastewater treatment

\section{Introduction}

Over the past decades, the requirements of the treated wastewater quality have become more stringent. To meet the new standards conventional activated sludge processes and reactor configurations were further developed and the biological treatment technologies were combined with other processes such as chemical treatment, microfiltration, ozonation, etc. [1], [2].

The basis of wastewater treatment technologies is the conventional activated sludge process, whose efficiency is strongly affected by the composition of the microbial community forming in the activated sludge flocks [3]. Following the biodegradation processes the secondary sedimentation is also highly affected by the bacterial culture 
forming activated sludge flocks. The species diversity, structure and texture of the bacterial culture can only be indirectly controlled in the treatment process by the design of the reactor, aerated and non-aerated reactor combinations, the rate of removed excess sludge, the rate of sludge recirculation and the F/M ratio [4].

Controlling the structure and through this the settling properties of activated sludge flocks is difficult, and it can significantly impair the overall efficacy of the treatment process if secondary sedimentation fails [5].

To overcome this problem some activated sludge systems have been retrofitted to Integrated Fixed Film Activated Sludge (IFFAS) process [6]. IFFAS is an improved Moving Bed Biofilm Reactor (MBBR) process where biofilm carrier technology is integrated into the conventional activated sludge reactors. The hybrid process enables activated sludge systems to achieve significant development in treatment efficiency without increasing Mixed Liquor Suspended Solids (MLSS) concentrations in the process [7], [8].

According to previous studies the modification of the bioreactor configuration using anoxic selectors can improve the settling properties of the activated sludge as well [9].

In recent years, PolyVinyl Alcohol (PVA)-gels have been applied for aerobic and anaerobic wastewater treatment as biomass carriers [10], [11], [12], [13]. According to the studies, applying these carriers has several benefits compared to the conventional activated sludge flocks, and to other types of carriers, however, they have not been used widespread in communal wastewater treatment.

Within the framework of the 3/081/2004 National Research, Development and Innovation Office (NKFP) research project at the Department of Sanitary and Environmental Engineering, Budapest University of Technology and Economics the use of artificial hydrogel micro-carriers were applied in laboratory scale wastewater treatment experiments aiming to improve the settling properties of the biomass [14], [15].

In this paper the nitrification process and the change of the settling properties of the biomass were examined and compared using PVA-PAA hydrogel micro-carrier and conventional activated sludge process under different operating conditions.

\section{Materials and methods}

In order to find the optimal characteristics (shape and size of the micro-carriers, porosity, the colonization and synthetizing characteristics, biodegradation, mechanical stability, settling behavior, etc.) more than 40 types of hydrogels were tested in the preliminary phase of the research. Gels were synthetized by the Department of Physical Chemistry and Materials Science of the Budapest University of Technology and Economics. According to the results of the preliminary bacterial colonization experiments the PVA-PAA hydrogel synthesized with embedded starch granules was most suitable for the wastewater technology requirements. PVA-PAA hydrogel microcarriers with an average diameter of $150-400 \mu \mathrm{m}$ were tested in laboratory scale wastewater technology experiments. The bacterial culture was colonized on the surface of the gel beads and formed microscopic scale bioreactors (immobilized 
microorganisms adhered to hydrogel surfaces on and within the gel structure) for pollutant removal [14].

The PVA-PAA hydrogel beads have a special texture (porosity) and $95-98 \%$ water content. The key question was to set appropriate environmental conditions for biofilm development on the surface of the hydrogel micro-carriers. Different inoculation procedures were tested in the preliminary stage of the research, and the colonization strategies of the hydrogel surface were optimized to achieve strong biofilm development. The inoculation procedure was evaluated using earlier experiences [14]; the duration of this phase was around 3 weeks. Temperature, $\mathrm{pH}$, feed water composition, shearing forces, dissolved oxygen level were controlled in the experiment. Two parallel laboratory-scale Sequenced Batch Reactors (SBRs) (conventional activated sludge reactor and the hydrogel micro-carriers biofilm reactor with capacities of 6.0-6.8 L) were operated with identical hydraulic and pollutant loads on fed-batch basis. The operation parameters of the SBR reactor are shown in Table I. During the experiments Volatile Suspended Solids/Total Suspended Solids (VSS/TSS) concentration in the conventional activated sludge SBR was around $1.5 / 2.25 \mathrm{~g} / \mathrm{L}$ and around 3.2/4.8 g/L in the hydrogel based SBR (around $2.5 \mathrm{~g} / \mathrm{L}$ without the gels).

Table I

The cycles of the SBR reactors

\begin{tabular}{|c|c|c|c|}
\hline & $\begin{array}{c}\text { Hydrogel based } \\
\text { SBR }\end{array}$ & $\begin{array}{c}\text { Conventional } \\
\text { activated sludge SBR }\end{array}$ & Unit \\
\hline Cycle length & 240 & 240 & $\min$ \\
Aeration phase & 230 & 210 & min \\
Settling phase & 10 & 30 & min \\
\hline
\end{tabular}

The operational parameters were identical except the settling period times (in the case of the hydrogel reactors shorter settling periods were needed). The feed wastewater was partially treated wastewater from the South-Pest Wastewater Treatment Plant. Organic matter was removed from the feed water in the treatment plant in the course of activated sludge process. Feed water was collected after the secondary settling tanks; nitrification was not realized in the activated sludge process, the characteristic parameters of feed wastewater are shown in Table II. The duration of the feeding was about 5 minutes and started with the aeration phase in both reactors.

The biofilm development on gel beads was monitored up by microscopic analysis and activity measurements. The bacterial activity on hydrogel beads was analyzed and compared to the conventional activated sludge in laboratory tests. The efficiency of the biodegradation process, nitrification and denitrification rates was monitored. The shear forces were influenced by a central vertical shaft mixer with the suitable mixing intensity according to the earlier experiences [14].

The hydrogel based bioreactor was filled with $700 \mathrm{~mL}$ volume of PVA-PAA hydrogel micro-carriers to provide colonization surface for wastewater bacteria. Hydrogel micro-carriers were inoculated by autotrophic nitrifying bacteria of wastewater origin. The development of the biofilm morphology on the micro-carriers was monitored by microscopic analysis and bacterial activity measurements. 
Table II

Parameters of the feed wastewater

\begin{tabular}{|c|c|c|c|c|}
\hline Parameter & Min & Max & Average & Unit \\
\hline Temperature & 17 & 21 & 19 & ${ }^{\circ} \mathrm{C}$ \\
pH & 6.5 & 7.6 & 7.2 & - \\
Conductivity & 600 & 1200 & 867 & $\mu \mathrm{S} / \mathrm{cm}$ \\
Dissolved oxygen & 0 & 0 & 0 & $\mathrm{mg} / \mathrm{L}$ \\
COD & 70 & 250 & 110 & $\mathrm{mg} / \mathrm{L}$ \\
TSS & 15 & 35 & 31 & $\mathrm{mg} / \mathrm{l}$ \\
PO $_{4}-\mathrm{P}$ & 0.5 & 1.5 & 1.2 & $\mathrm{mg} / \mathrm{L}$ \\
Ammonium-N & 38 & 85 & 53 & $\mathrm{mg} / \mathrm{L}$ \\
Nitrite-N & 4 & 10 & 6 & $\mathrm{mg} / \mathrm{L}$ \\
Nitrate-N & 2 & 10 & 5 & $\mathrm{mg} / \mathrm{L}$ \\
\hline
\end{tabular}

To compare the settling properties, the Sludge Volume Index (SVI) changes were measured of the immobilized bacterial culture of the hydrogel and conventional activated sludge. The initial TSS and VSS concentration and the sludge levels were investigated, conventional Imhoff-glass (Capacity: $1 \mathrm{~L}$ ) was used.

To determine the settling properties of the different biomass types SVI was measured for 30 minutes settling periods. In the meantime, $\mathrm{SVI}_{\mathrm{X}}$ for $\mathrm{SVI}_{1}, \mathrm{SVI}_{3}, \mathrm{SVI}_{5}$, $\mathrm{SVI}_{6}, \mathrm{SVI}_{12}, \mathrm{SVI}_{20}$ and $\mathrm{SVI}_{30}$ (for 1, 3, 5, 6, 12, 20 and 30 min sedimentation) were also calculated based on sedimentation experiments. $\mathrm{SVI}_{\mathrm{X}}$ was calculated similar than the conventional SVI value, $V_{X}(\mathrm{~mL} / \mathrm{L})$ divided by the MLSS $(\mathrm{g} / \mathrm{L})$ value $\left(V_{X}\right.$, settled sludge volume after $x$ minutes).

The effects of the filamentous organisms on the settling properties of the hydrogelmodified sludge were also examined. The operating parameters of the parallel SBR reactors (conventional and hydrogel-modified active sludge) were set in order to stimulate the growth of the filamentous organisms. Low Dissolved Oxygen (DO) level can favor the growth of filamentous microorganisms [16], thus the dissolved oxygen concentration was set in the reactor below $0.3 \mathrm{mg} / \mathrm{L}$. After more than two weeks of exposure the settling property changes of both the conventional and the hydrogelmodified activated sludge were measured.

The hydrogel-modified sludge reactor was operated for more than one year. The $\mathrm{SVI}_{\mathrm{X}}$ measurements started after 3 months from the beginning of the experiment.

\section{Results}

Optimal bacterial adhesion and biofilm structure developed on the porous structure of hydrogel micro-carriers under appropriate hydraulic conditions of the breeder reactor. The increased porosity of the surface proved to be evidently favorable for the attachment of suspended cells and small bacterial flocks. This consideration was essential in the course of the colonization process. Therefore, porosity of the PVA-PAA hydrogel was enhanced during the preparation treatment by the Department of Physical Chemistry and Materials Science of the Budapest University of Technology and Economics. During the docking phase, the contact frequency between the gels and the 
bacteria is generally low, so the attachment to and detachment from the gel surface are highly influenced by the hydraulic conditions and the shear forces in the reactor [17]. The fine tuning of the hydraulic conditions was essential to control the colonization process and thereby influence the development of the biofilm structure and biofilm thickness [18]. Therefore, the shear forces were optimized according to the growth rate of the bacterial community (mostly autotrophic microorganisms). Fig. 1- Fig. 2 illustrate the phases of biofilm development, to reach the suitable shear forces.

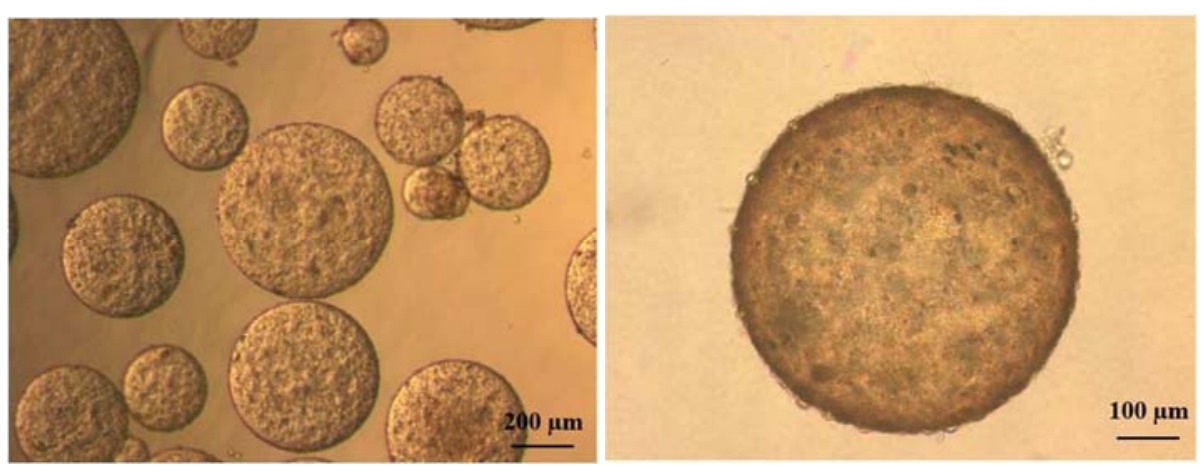

Fig. 1. Micro-carriers after the bacterial adhesion phase (left) and the optimal biofilm structure as a results of the biofilm development (right)
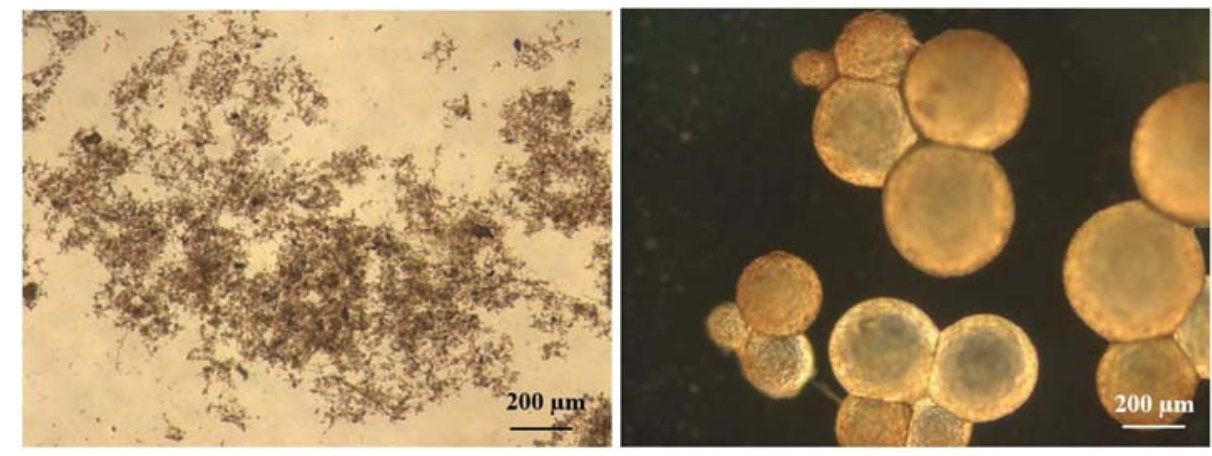

Fig. 2. Activated sludge flocks structure of bacterial colonies in the parallel experiments (left) and on micro-carriers (right) under optimal condition

Since the biofilm structure (i.e., oxygen diffusion limitations, formation of oxic and anoxic zones) determines the technological capabilities of the colonized micro-carriers it was expected that thick and homogenous biofilm on the micro-carriers could enhance the settling velocities. In the experiments, homogenous and compact biofilm could be developed on the surface of the micro-carriers by the enhancement of the porosity of the hydrogel, by the regulation of the shear forces in the breeding reactor and by the application of a suitable inoculation procedure. 
It was proved that by the applied colonization processes $95-99 \%$ of the suspended biomass could be adhered onto the surface of the hydrogels, thus almost the whole biomass was immobilized as hydrogel-adhered bacterial cells.

Bacterial activity was measured in comparative studies within optimal operational conditions for nitrifying bacteria (high dissolved oxygen concentration around 4-5 mg/L and ammonium-N, relatively low organic matter concentration and low heterotrophic biomass). Fig. 3 shows the development of nitrogen forms during aeration phase in the conventional activated sludge reactor and in the reactor filled with hydrogel microcarriers. Usually nitrification can be divided into two different processes, which are the formation of $\mathrm{NO}_{2}-\mathrm{N}$ from $\mathrm{NH}_{4}-\mathrm{N}$, caused by the Nitrosomonas bacteria group and the formation of $\mathrm{NO}_{3}-\mathrm{N}$ from $\mathrm{NO}_{2}-\mathrm{N}$ caused by Nitrobacter bacteria group. The activity of Nitrosomonas bacteria group was calculated from the decrease of $\mathrm{NH}_{4}-\mathrm{N}$, while the formation of $\mathrm{NO}_{3}-\mathrm{N}$ shows the activity of Nitrobacter bacteria (Fig. 4). Activity $[\mathrm{mg} / \mathrm{h} / \mathrm{g}]$ stands for the $\mathrm{mg} \mathrm{N}$-form (ammonium or nitrate $\mathrm{N}$ ) removed/formed in a onehour-long period calculated for $1 \mathrm{~g}$ of biomass, which was considered as the organic matter concentration without hydrogels in the reactors.

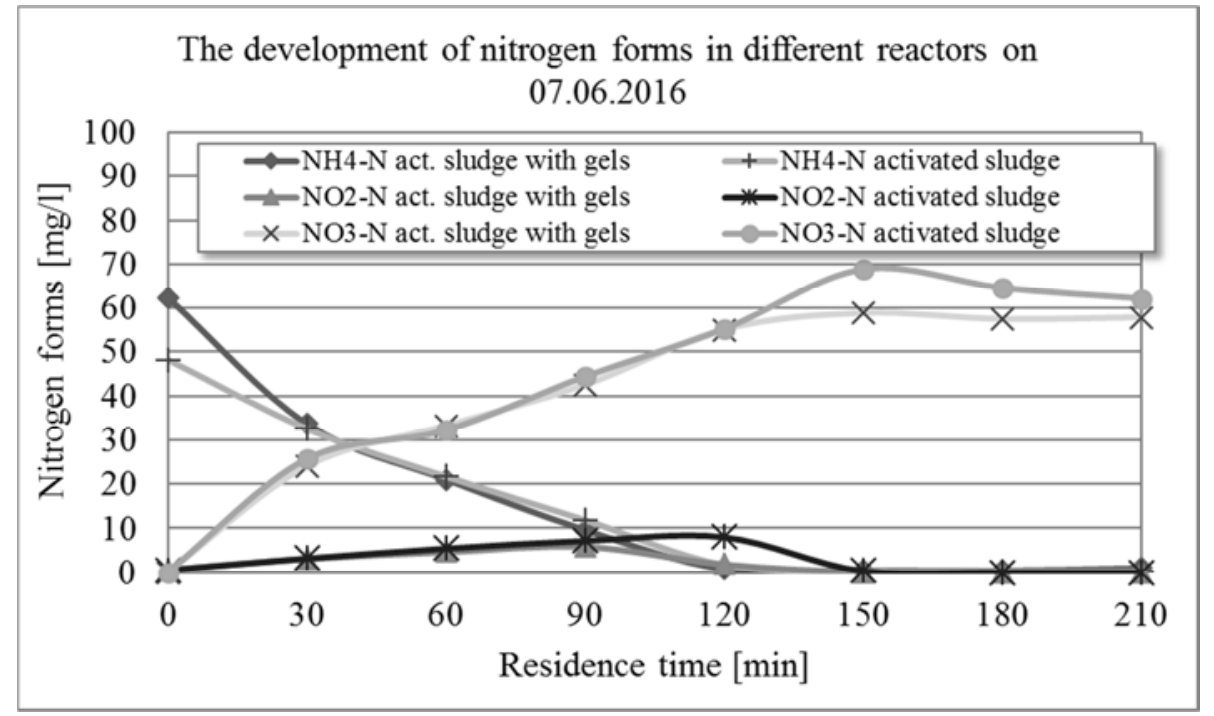

Fig. 3. The bacterial activity of the activated sludge modified by hydrogels and the conventional activated sludge flocks under optimal condition

Fig. 5 shows the activated sludge flocks and the modified culture under optimal conditions. Based on the operational experiences it was found that in reactors operating with hydrogels the activity and settling properties of the bacteria are highly independent of the load and the operating conditions of the reactors. However, the properties of the biomass in the conventional activated sludge reactor were remarkably affected by these operational parameters. The settling properties of the bacteria formed on hydrogels were examined for each different operation setting. 
As the dissolved oxygen concentration decreased (0.1-0.2 mg/L) filamentous organisms developed. Fig. 6 illustrates the appearance of filamentous organisms in the conventional activated sludge reactor and on the hydrogel micro-carriers.

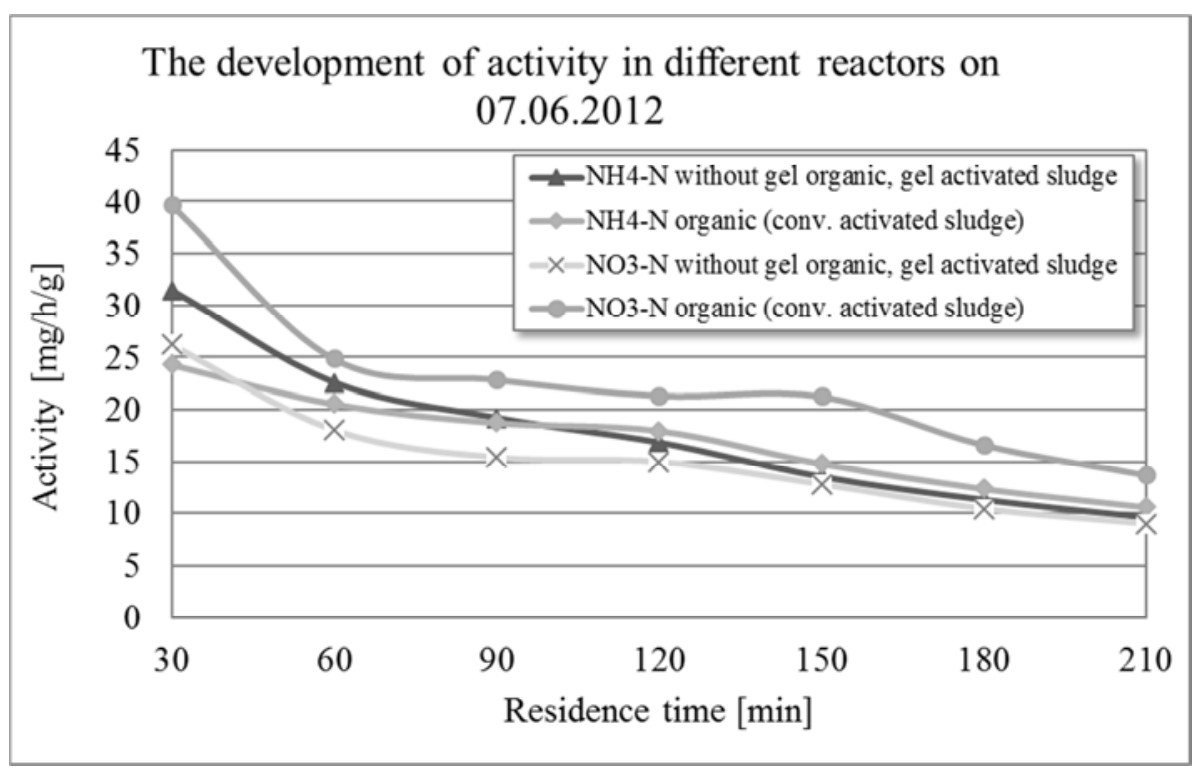

Fig. 4. The bacterial activity of the activated sludge modified by hydrogels and the conventional activated sludge flocks under optimal condition

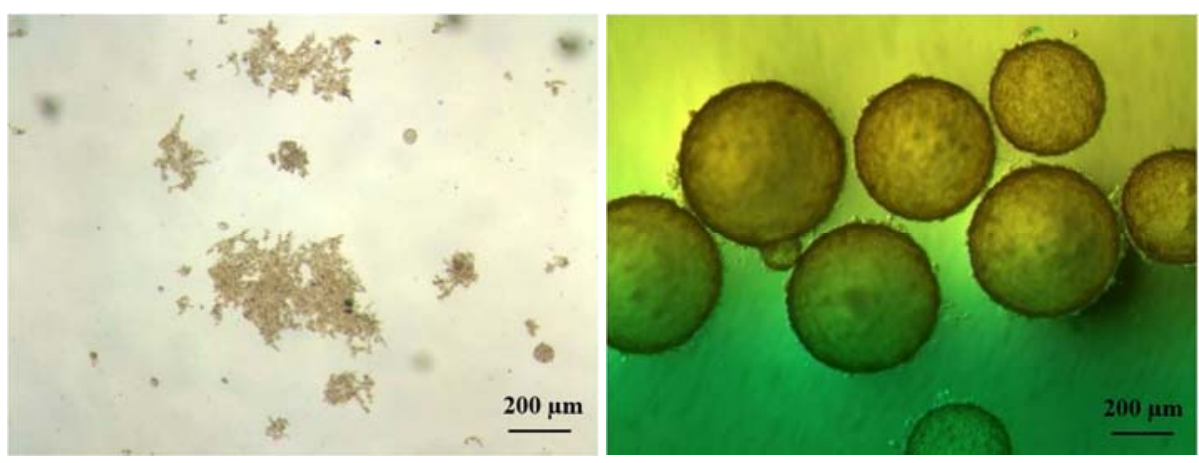

Fig. 5. Conventional activated sludge flocks (left) and bacterial community on hydrogel microcarriers (right) under optimal condition

The sedimentation tests were performed with biomass developed under optimal operational conditions and also in the presence of filamentous organisms. Fig. 7 illustrates the sedimentation properties of the bacterial cultures in the case of optimal reactor operation and Fig. 8 shows the changing sedimentation parameters after the development of filamentous microorganisms. The organic matter and dry matter 
concentration of the thickened sludge (for the micro-carriers and activated sludge as well) were calculated from the initial concentrations and the actual position of the sludge blanket.
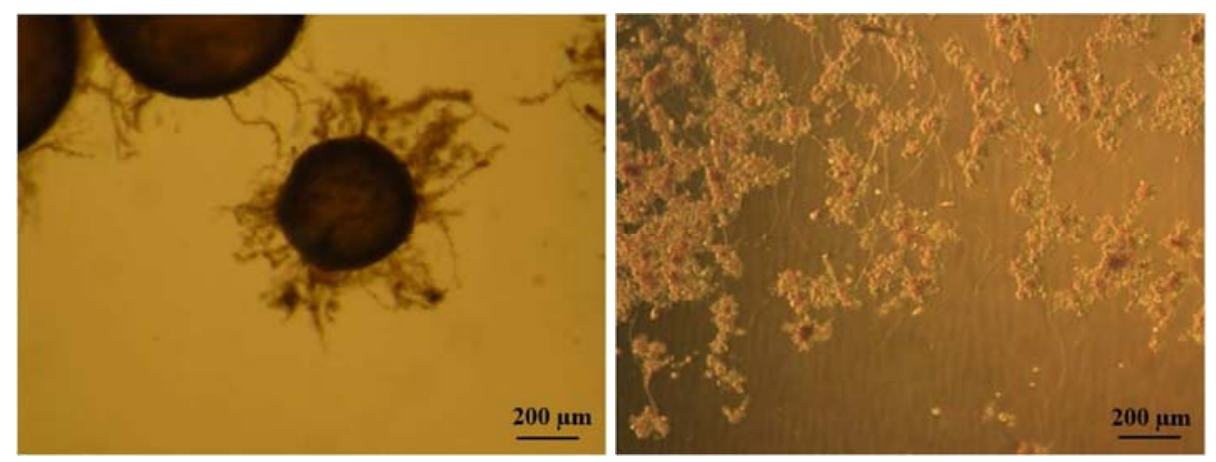

Fig. 6. Impact of filamentous organisms on conventional activated sludge flocks (right) and on hydrogel micro-carriers (left)

Based on the results the following observations were made:

- The sedimentation properties of the hydrogel system are significantly better than the traditional activated sludge systems. The required time for sedimentation of the hydrogel based reactors was about 5 times less than that of the conventional system. The hydrogel based SBR reactor could be operated with 5 minutes sedimentation cycle, in contrast more than 30 minutes sedimentation time had to be applied in the case of traditional activated sludge system;

- Regarding micro-carriers the $\mathrm{SVI}_{\mathrm{X}}$ after a 3 minute sedimentation time was around $29 \mathrm{~mL} / \mathrm{g}$ (the conventional activated sludge system had around $200 \mathrm{~mL} / \mathrm{g}$ ) and this value still was $30 \mathrm{~mL} / \mathrm{g}$ after 30 minutes in the case of activated sludge without gels. According to the results the bacteria immobilized on hydrogel micro-carriers have excellent settling characteristics and the necessary settling time was only 3 minutes under optimal operation conditions;

- The VSS concentration in the supernatant after 3 minutes was around $0.05 \mathrm{~g} / \mathrm{L}$ (the initial VSS concentration was $4.2 \mathrm{~g} / \mathrm{L}$ with gels, and $2.62 \mathrm{~g} / \mathrm{L}$ without gels). In the case of the hydrogel fixed bacterial culture the efficiency of the sedimentation was around $99 \%$;

- After the appearance of the filamentous organisms (Fig. 8) the 30 minutes $\mathrm{SVI}_{\mathrm{X}}$ of the traditional activated sludge system multiplied but the 30 minutes $\mathrm{SVI}_{\mathrm{X}}$ of the system hydrogel fixed biomass did not showed significant changes. It should be that the necessary sedimentation time of the hydrogel based system increased from 3 minutes to 10 minutes, which indicates still very good operational conditions in the presence of filamentous microorganisms. After the 10 minute sedimentation times the $\mathrm{SVI}_{\mathrm{X}}$ was $40-50 \mathrm{~mL} / \mathrm{g}$ which shows promising sedimentation properties. 

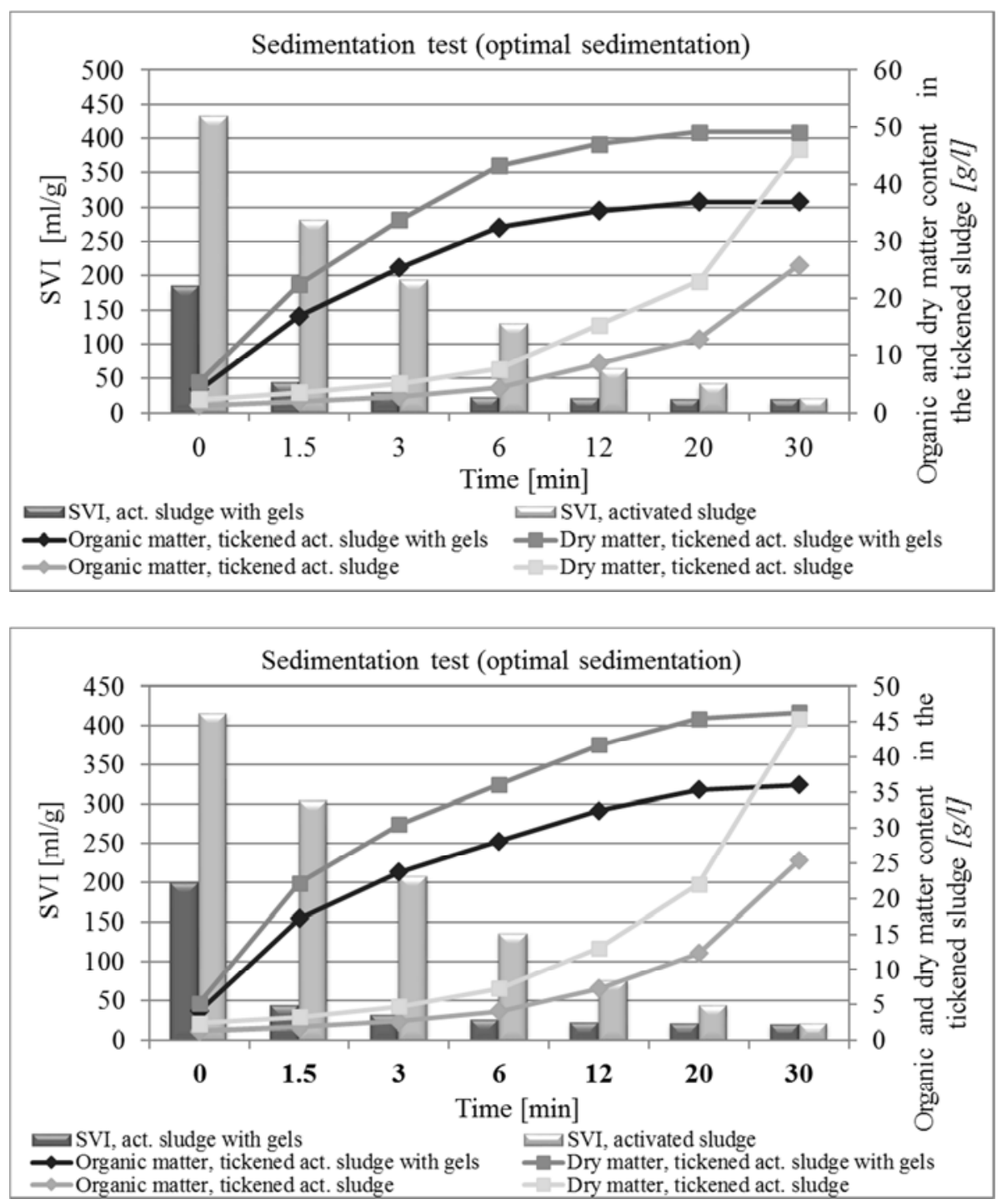

Fig. 7. The results of the sedimentation tests (in the case of optimal operating conditions) on two different days

\section{Conclusions}

Some of the key parameters of the biological wastewater treatment, namely the structure and the morphological features of the activated sludge flocks, can only be controlled by indirect methods. The present research aimed to find and prove suitable opportunities control directly these key parameters (particle size distribution, density, 
etc.). Primarily hydrogels were tested in this study, which are suitable for bacterial adherence and colonization. According to the preliminary bacterial adhesion tests, the copolymer of PVA-PAA was proven to be the most suitable carrier. Analyzing various reactors with different design, size and operation, some special examinations were carried out in order to understand the favorable effects of the hydrogels and to determine the necessary environmental conditions for gel surface colonization.
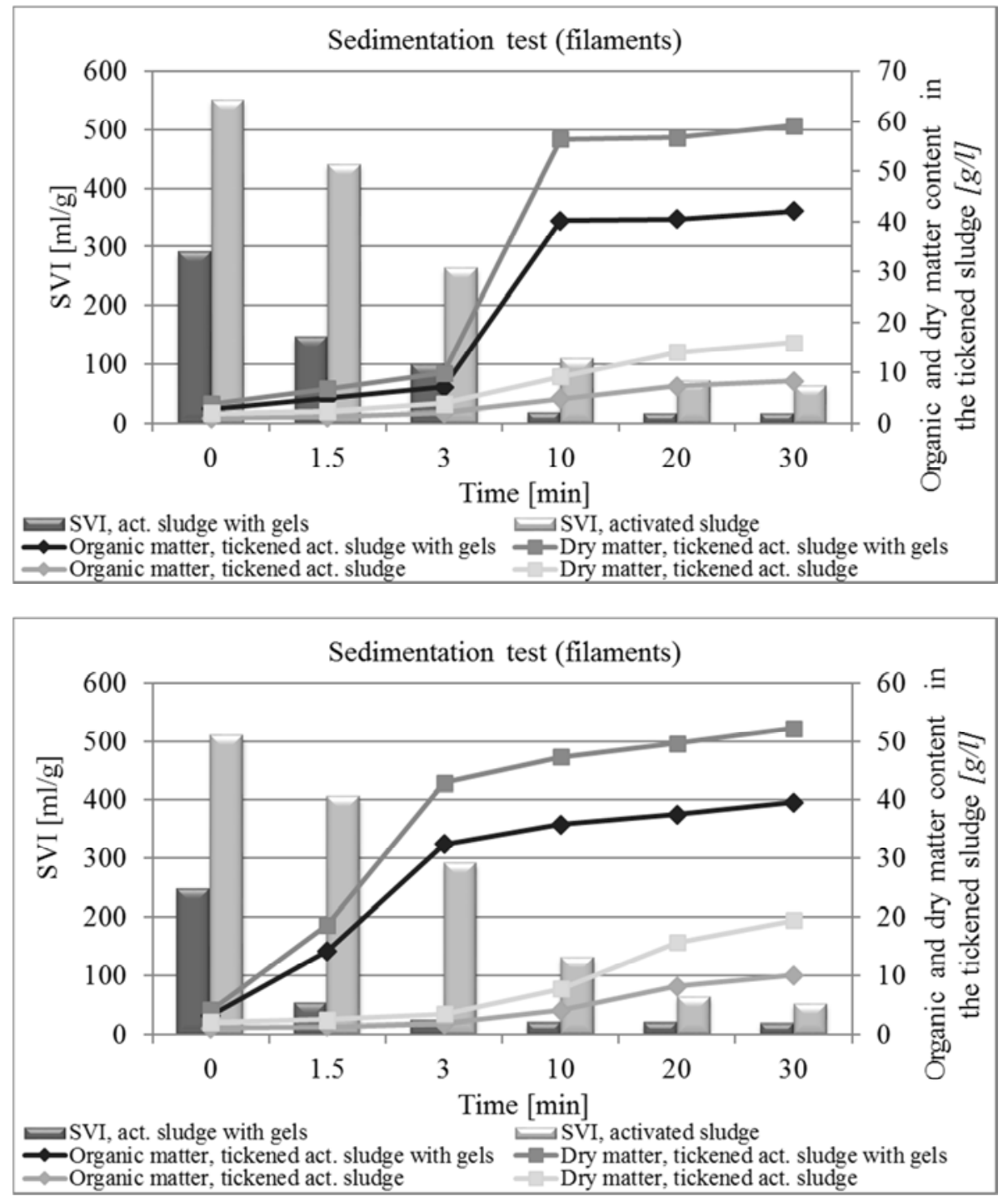

Fig. 8. The results of the sedimentation tests (in the case of filamentous bacterial growth) on two different days 
Bacterial activity measurements, microscopic tests and related calculations were carried out in laboratory-scale wastewater treatment experiments. Compact structure and active autotrophic bacterial biofilm can form on the surface of PVA-PAA pearls, which can be used for efficient nitrification. By the application of the appropriate inoculation processes $95-99 \%$ of the suspended activated sludge biomass will be adhered on the surface of the hydrogels, so almost the whole biomass concentration was found to be immobilized on the hydrogel-defined micro-reactors. It means that nearly the entire biomass can be controlled by the hydrogels.

The sedimentation properties of the conventional activated sludge and the hydrogel fixed biomass system were measured and compared among optimal operational conditions. According to the results the sedimentation properties the immobilized system was more favorable than the activated sludge flocks. The sedimentation features of hydrogel system are significantly more advantageous compared to the traditional activated sludge systems. In the case of the hydrogel system the SBR bioreactor could be operated with 5 minute sedimentation time $\left(\mathrm{SVI}_{\mathrm{X}}\right.$ after 5 minute sedimentation is $45 \mathrm{~mL} / \mathrm{g}$ ), whereas more than 30 minutes sedimentation time had to be applied in the case of traditional activated sludge system.

The development of filamentous microorganisms is a frequent operational problem hindering the settling process as they alter the Stokes radius of the flocks and form bridges amongst the settling flocks. These can corrupt the efficiency of the biological activity and the effectiveness of the phase separation. In the case of the bacterial flocks formed by the application of PVA-PAA hydrogel this problem did not occur even under extreme operating conditions. The Sludge Volume Index $\left(\mathrm{SVI}_{\mathrm{X}}\right)$ of the conventional activated sludge flocks and the artificial flocks with PVA-PAA was measured and compared by sedimentation analysis. The results showed that the modified system has clearly more favorable settling properties and also that in the case of the gel-modified flocks the problem of filaments does not induce deterioration in the efficiency of the gravitational phase separation.

\section{Acknowledgement}

The project was financed by the 3/081/2004 NKFP research project at the Department of Sanitary and Environmental Engineering, Budapest University of Technology and Economics and gel synthesis was performed by the Department of Physical Chemistry and Materials Science of the Budapest University of Technology and Economics which contributions are highly appreciated by the authors.

\section{References}

[1] Oller I., Malato S., Sanchez-Pérez J. A. Combination of advanced oxidation processes and biological treatment for wastewater decontamination, A review, Science of Total Environment, Vol. 409, No. 20, 2011, pp. 4141-4166.

[2] Pikorova T., Hlavinek M. P., Drtil M., Rusnak D. Operation of household wastewater treatment plant equipped with membrane module, Pollack Periodica, Vol 5, No. 3, 2010, pp. 133-142. 
[3] Moretti C. J., Das D., Kistner B. T., Gullicks H., Hung, Y. T. Activated sludge and other aerobic suspended culture processes, Water, Vol. 3, 2011, pp. 806-818.

[4] Gulyás P., Fleit E., Melicz Z., Bognár F. Methodology for microscopic investigation of biological wastewater treatment plants, (in Hungarian) Eötvös József Főiskolai Kiadó, Baja, 2015.

[5] Dunkel T., de León Gallegos E. L., Schönsee C. D., Hesse T., Jochmann M., Wingender J., Denecke M. Evaluating the influence of wastewater composition on the growth of microthrix parvicella by GCxGC/qMS and real-time PCR, Water Research, Vol. 88, 2016, pp. 510-523.

[6] Mahendran B., Lishman L., Liss S. N. Structural, physicochemical and microbial properties of flocks and biofilms in integrated fixed-film activated sludge (IFFAS) systems, Water Research, Vol. 46, No. 16, 2012, pp. 5085-5101.

[7] Kim H. S., Gellner J. W., Boltz J. P., Freudenberg R. G., Gunsch C. K., Schuler A. J. Effects of integrated fixed film activated sludge media on activated sludge settling in biological nutrient removal systems, Water Research, Vol. 44, No. 5, 2010, pp. 1553-1561.

[8] Chu L., Wang J., Quan F., Xing X. H., Tang L., Zhang C. Modification of polyurethane foam carriers and application in a moving bed biofilm reactor, Process Biochemistry, Vol. 49, No. 11, 2014, pp. 1979-1982.

[9] Jobbágy A., Farkas F., Garai Gy., Sevella B., Oszoly T. Trial operation of a selector at the Northpest Wastewater Treatment Plant, Periodica Polytechnica, Chemical Engineering, Vol. 45, No. 1, 2001, pp. 41-52.

[10] Ali M., Oshiki M., Rathnayake L., Ishii S., Satoh H., Okabe S. Rapid and successful startup of anammox process by immobilizing the minimal quantity of biomass in PVA-SA gel beads, Water Research, Vol. 79, 2015, pp. 147-157.

[11] Li Z. G., Hira D., Fujii T., Furukawa K. Treatment capability and microbial community of anammox process using PVA gel bead as biomass carriers, Japanese Journal of Water Treatment Biology, Vol. 47, No. 4, 2011, pp. 137-145.

[12] Gani K. M, Singh J., Singh N. K., Ali M., Rose V., Kazmi A. A. Nitrogen and carbon removal efficiency of a polyvinyl alcohol gel based moving bed biofilm reactor system, Water Science and Technology, Vol. 73 No. 7. 2016, pp. 1511-1519.

[13] Zhang W., Wang D., Koga Y., Yamamoto T., Zhang L., Furukawa K. PVA-gel beads enhance granule formation in a UASB reactor, Bioresource Technology, Vol. 99, No. 17, 2008, pp. 8400-8405.

[14] Fleit E., Melicz Z., Sándor D., Zrínyi M., Filipcsei G., László K., Dékány I., Királ, Z. IASON - Intelligent activated sludge operated by nanotechnology, Hydrogel carriers in wastewater treatment, Progress in Colloid and Polymer Science, Vol. 135, 2008, pp. 209-217.

[15] Sándor D., Fetter É., Fleit E. Use of nanotecnologically constructed micro-reactors in MBR system, Pollack Periodica, Vol. 5, No. 2, 2010, pp. 141-153.

[16] Tchobanoglous G., Burton F. L., Stensel H. D. Wastewater engineering, Treatment and Reuse, (4 ${ }^{\text {th }}$ Ed.) Mc Graw Hill, NY, 2003.

[17] Celmer, D., Oleszkiewicz, J. A., Cicek, N. Impact of shear force on the biofilm structure and performance of a membrane biofilm reactor for tertiary hydrogen-driven denitrification of municipal wastewater, Water Research, Vol. 42, No. 12, 2008, pp. 3057-3065.

[18] Liu Y., Tay J. H. The essential role of hydrodynamic shear force in the formation of biofilm and granular sludge, Water Research, Vol. 36, No. 7, 2002, pp. 1653-1665. 